\title{
Pengaruh Pemberian Mikroorganisme Lokal dan NPK terhadap Pertumbuhan Bibit Kakao (Theobroma cacao L.)
}

\section{The Effect of Local Microorganism and NPK on the Growth of Cocoa Seedling (Theobroma cacao L.)}

\author{
Ulvie Delfiana $^{1}$, Nanda Mayani ${ }^{1}$, Erida Nurahmi ${ }^{*}$ \\ ${ }^{1}$ Program Studi Agroteknologi, Fakultas Pertanian, Universitas Syiah Kuala
}

\begin{abstract}
Abstrak. Penelitian ini bertujuan untuk mengetahui pengaruh beberapa konsentrasi mikroorganisme lokal dan NPK terhadap pertumbuhan bibit kakao. Penelitian ini dilaksanakaan di Kebun Percobaan 2 dan Labaratorium Hortikultura, Jurusan Agroteknologi Fakultas Pertanian Universitas Syiah Kuala, Banda Aceh dari bulan Juni sampai Agustus 2018. Penelitian ini menggunakan Rancangan Acak Kelompok pola faktorial 4x4 dan 3 ulangan, sehingga terdapat 48 satuan percobaan dan dilanjutkan dengan uji Beda Nyata Jujur taraf $5 \%$ pada hasil uji $\mathrm{F}$ yang signifikan. Faktor pertama adalah konsentrasi mikroorganisme lokal dengan 4 taraf yaitu: 0, 75, 150 dan $225 \mathrm{cc} \mathrm{L}^{-1}$ air. Faktor kedua adalah dosis pupuk NPK dengan 4 taraf yaitu $0,7.5,15$ dan $22.5 \mathrm{~g} /$ polybag. Parameter yang diamati adalah tinggi tanaman, diameter pangkal batang, jumlah daun, berat berangkasan basah dan berat berangkasan kering. Hasil penelitian menunjukkan bahwa, perlakuan beberapa konsentrasi mikroorganisme lokal berpengaruh tidak nyata terhadap semua parameter. Pemberian pupuk NPK berpengaruh sangat nyata terhadap jumlah daun bibit kakao umur 8 MST dan berpengaruh nyata pada jumlah daun bibit kakao umur 12 MST, juga berpengaruh nyata terhadap berat berangkasan basah. Pertumbuhan bibit kakao terbaik diperoleh pada dosis pupuk NPK $15 \mathrm{~g} /$ polybag. Terdapat interaksi tidak nyata antara perlakuan konsentrasi mikroorganisme lokal dan dosis pupuk NPK.
\end{abstract}

Kata kunci : Mikroorganisme lokal, konsentrasi, NPK dan bibit kakao.

\begin{abstract}
The purposes of this research were to know the effect of several concentrations of local microorganism and NPK on the growth of cocoa seedlings. This research was conducted at Experimental Garden 2 and Horticulture Laboratory, Department of Agrotechnology, Faculty of Agriculture Syiah Kuala University, Banda Aceh from June to August 2018. This study used a Randomize Block Design of 4x4 factorial pattern with 3 replication, so that were 48 experimental units and continued with a Honestly Significance Difference $5 \%$ level on significant $F$ test result. The first factor is the concentration of local microorganism of 4 levels: $0,75,150$ and $225 \mathrm{cc} \mathrm{L}^{-1}$ water. The second factor is the dose of NPK fertilizer of 4 levels: $0,7.5,15$ and $22.5 \mathrm{~g} / \mathrm{polybag}$. Parameters observed were plant height, stem base diameter, number of leaves, wet weight and dry weight. The result showed that the treatment of several concentrations of local microorganism had unsignificantly effect on all parameters. NPK fertilizer application has a very significant effect on the number of cocoa seedlings aged 8 WAP and has a significantly effect on cocoa seedlings aged $12 \mathrm{WAP}$, it also has a significantly effect on the weight of wet seedlings. The best growth of cocoa seddlings is obtained at a dose of NPK fertilizer $15 \mathrm{~g} / \mathrm{polybag}$. There is unsignificantly effect between the treatment of local microorganism concentrations and NPK fertilizer dosage.
\end{abstract}

Keywords: Local microorganism, concentration, NPK and cocoa seeds.

\section{PENDAHULUAN}

Kakao (Theobroma cacao L.) adalah salah satu komoditi unggulan dari sub sektor perkebunan. Komoditas kakao mendukung perekonomian Indonesia yang berperan dalam menambah sumber devisa negara dan menyediakan lapangan pekerjaan yang cukup besar. Saat ini kemajuan pengembangan agroindustri juga didukung dari komoditas kakao (Rifin dan Nurdiyani, 2007).

Penggunaan pupuk anorganik mampu meningkatkan hasil pertanian di Indonesia. Namun tanpa disadari penggunaan pupuk anorganik secara terus menerus berdampak tidak 
baik bagi sifat fisik, kimia dan biologi tanah (Pranata, 2004). Salah cara yang dapat dilakukan untuk meminimalisir kerusakan lahan pertanian yaitu dengan memanfaatkan limbah disekitar lingkungan, dan memberikan efek yang baik bagi pertumbuhan bibit kakao.

Upaya yang dapat dilakukan dalam usahatani tanpa menggunakan bahan-bahan kimia yang akan merusak lingkungan adalah dengan pemanfaatan mikoorganisme lokal (MOL). MOL merupakan mikroorganisme lokal yang dimanfaatkan untuk menyuburkan tanaman, memperbaiki struktur tanah serta menjadi solusi bagi petani untuk menuju pertanian yang ramah lingkungan dan terbebas dari bahan-bahan kimia. Bahan dasar pembuatan mol dapat berupa limbah rumah tangga, pertanian atau peternakan yang mudah didapatkan dan mudah diolah serta penggunaan MOL dapat menghemat biaya produksi yaitu 20-25\%. Umumnya mikoorgnisme lokal dimanfaatkan sebagai starter dalam proses pembuatan pupuk organik padat maupun pupuk organik cair (Ramli dan Parawansa, 2014).

Kombinasi antara pupuk organik dengan pupuk anorganik dapat dimanfaatkan lebih efektif oleh tanaman dalam penyerapan hara. Salah satu pupuk anorganik yang dapat digunakan adalah pupuk NPK majemuk (Yulia et al., 2016). Salah satu pupuk NPK majemuk yang dapat digunakan yaitu pupuk NPK Phonska. Pupuk NPK Phonska mengandung 15\% N, $15 \% \mathrm{P}_{2} \mathrm{O}_{5}$ dan $15 \% \mathrm{~K}_{2} \mathrm{O}$ (Jannah, 2014).

Berdasarkan uraian diatas maka perlu dilakukan penelitian mengenai pengaruh pemberian mikroorganisme lokal dan NPK terhadap pertumbuhan bibit kakao.

\section{METODE PENELITIAN}

Penelitian ini dilaksanakan di Kebun Percobaan 2 dan Laboratorium Hortikultura, Fakultas Pertanian Universitas Syiah Kuala, Darussalam-Banda Aceh, dimulai 13 Mei sampai 8 Agustus 2018.

\section{Alat}

Alat yang digunakan dalam penelitian ini berupa cangkul, gembor, meteran, jangka sorong, polybag $25 \mathrm{~cm} \times 30 \mathrm{~cm}$ atau isi $5 \mathrm{~kg}$, paranet, ayakan 6 mesh, oven, timbangan digital, $\mathrm{pH}$ meter, amplop, kertas label, kamera dan alat tulis. Sedangkan peralatan yang digunakan dalam pembuatan MOL adalah ember, pisau, saringan, blender dan jerigen.

\section{Bahan}

Bahan yang digunakan dalam penelitian ini berupa benih kakao klon Sulawesi 2 (S2) sebanyak 144 benih yang diperoleh dari kebun petani di Desa Puduek, Kecamatan Trienggadeng, Kabupaten Pidie Jaya, tanah diperoleh dari L.A Garden Banda Aceh, pupuk kandang sapi, sekam padi, goni dan pupuk NPK Phonska (15:15:15) sebanyak 1,62 kg. Sedangkan bahan untuk pembuatan MOL yaitu $9 \mathrm{~kg}$ limbah kulit pisang, $9 \mathrm{~kg}$ limbah kulit pepaya (dapat digunakan dari semua jenis), 9 liter air kelapa serta 1,8 kg gula merah.

\section{Metode Penelitian}

Penelitian ini menggunakan Rancangan Acak Kelompok (RAK) pola faktorial yang terdiri atas 2 (dua) faktor dengan pola $4 \times 4$ dengan 3 ulangan sehingga terdapat 48 satuan percobaan. Tiap unit percobaan terdiri dari 3 tanaman sehingga terdapat 144 tanaman. Faktor pertama adalah konsentrasi mikroorganisme lokal (M), terdiri atas 4 taraf yaitu: $\mathrm{M}_{0}$ (kontrol), $\mathrm{M}_{1}$ (75 cc L $\mathrm{c}^{-1}$ air), $\mathrm{M}_{2}$ (150 cc L $\mathrm{c}^{-1}$ air) dan $\mathrm{M}_{3}$ (225 cc L $\mathrm{L}^{-1}$ air). Faktor kedua adalah dosis pupuk 
NPK (P) yang terdiri atas 4 taraf yaitu: $\mathrm{P}_{0}$ (kontrol), $\mathrm{P}_{1}$ (7,5g/polybag), $\mathrm{P}_{2}(15 \mathrm{~g} /$ polybag) dan $\mathrm{P}_{3}(22,5 \mathrm{~g} /$ polybag$)$.

\section{Pembuatan MOL Limbah Kulit Pisang dan Pepaya}

Bahan baku pembuatan MOL yaitu $9 \mathrm{~kg}$ limbah kulit pisang dan pepaya (dapat digunakan dari semua jenis), 9 liter air kelapa dan $1,8 \mathrm{~kg}$ gula merah. Pembuatan MOL dilakukan 3 kali yaitu setiap 2 minggu sebelum MOL diaplikasikan. Setiap satu kali pembuatan hanya dibutuhkan $3 \mathrm{~kg}$ limbah kulit pisang dan pepaya, 3 liter air kelapa dan $600 \mathrm{~g}$ gula merah. Kulit pisang dan kulit pepaya diiris-iris, dimasukkan $600 \mathrm{~g}$ gula merah dan air kelapa, kemudian diblender hingga hancur. Selanjutnya seluruh bahan tersebut dituang kedalam jerigen dan ditutup rapat. Selama 14 hari difermentasi, setiap harinya MOL dibuka dan diaduk. Disimpan ditempat yang tidak terkena cahaya matahari langsung. MOL yang berhasil, ditandai dengan perubahan bau asam atau berbau tape. Selanjutnya MOL sudah dapat diaplikasikan (Wijaya, 2017).

\section{Persiapan Tempat Pembibitan}

Pembersihan areal pembibitan dapat digunakan cangkul, untuk membersihkan gulma, semak, kayu dan sisa-sisa tanaman. Kemudian dipersiapkan wadah penyemaian dan media untuk pemindahan bibit kakao. Media penyemaian yang digunakan adalah goni basah.

\section{Pembuatan Naungan}

Pembuatan naungan bertujuan untuk menghindari bibit dari terpaan angin, hujan dan matahari secara langsung. Naungan dibuat dengan panjang $4 \mathrm{~m}$, lebar 5,3 $\mathrm{m}$ dan tinggi 1,9 $\mathrm{m}$ dengan tiang dari bambu dan atap dari paranet.

\section{Penyemaian Benih}

Benih kakao diambil pada bagian tengah buah atau pada $2 / 3$ bagian buah dengan tujuan untuk memperoleh keseragaman benih. Secara kuantitatif, benih yang berukuran besar memiliki jumlah cadangan makanan yang semkin banyak sehingga dapat mencukupi kebutuhannya dalam proses perkecambahan. Kemudian benih kakao dibersihkan lendirnya menggunakan abu sekam padi. Setelah itu benih dicuci menggunakan air mengalir. Sebelum penyemaian, benih kakao direndam terlebih dahulu dalam larutan fungisida Dithane $M-45$ dengan konsentrasi $2 \mathrm{~g} \mathrm{~L}^{-1}$ air selama 5 menit. Kemudian benih dikering anginkan selama 1 jam dan benih siap untuk dikecambahkan. Benih dikecambahkan pada goni basah untuk mempermudah saat proses pemindahan ke polybag utama. Untuk menjaga kelembaban dilakukan penyiraman pada sore hari.

\section{Persiapan Media Tanam}

Media tanam adalah campuran tanah dan pupuk kandang sapi yang telah diayak serta sekam padi dengan perbandingan 1:1:1. Kemudian dimasukkan ke dalam polybag ukuran 25 $\mathrm{cm} \times 30 \mathrm{~cm}$ atau isi $5 \mathrm{~kg}$, selanjutnya tanah diisi sesuai ukuran polybag.

\section{Pemindahan Kecambah Ke Polybag}

Pemindahan kecambah saat benih berumur 3 hari atau ditandai dengan munculnya radikula. Kemudian kecambah dipindahkan ke polybag dengan cara membuat lubang pada polybag yang telah diisi tanah sedalam jari telunjuk, dengan tujuan agar akar kecambah sebisa mungkin tetap lurus dalam lubang tanam. Kecambah ditanam pada lubang tanam yang telah dibuat sehingga radikula tidak rusak saat pindah tanam kemudian ditutup kembali menggunakan tanah dengan cara menekan perlahan. 


\section{Pemeliharaan}

Penyiraman bibit dilakukan pada pagi dan sore hari, namun disesuaikan dengan kondisi cuaca. Penyiangan gulma dilakukan secara manual dan pengendalian hama penyakit dilakukan jika tanaman terserang OPT, pengendalian dengan cara aplikasi pestisida sesuai anjuran.

\section{Pembongkaran Bibit}

Proses pembongkaran bibit dilakukan di akhir penelitian (12 MST). Seluruh bagian tanaman dipanen secara utuh dan dibersihkan akar dari sisa-sisa tanah. Setelah itu bibit ditimbang terlebih dahulu, kemudian dimasukkan ke dalam amplop sesuai dengan perlakuan untuk pengamatan parameter selanjutnya.

\section{Parameter Pengamatan}

\section{Tinggi Tanaman $(\mathbf{c m})$}

Tinggi tanaman diukur pada saat tanaman berumur 4, 8 dan 12 MST menggunakan meteran mulai dari permukaan tanah yang telah diberikan tanda berupa kayu sebagai standar pengukuran sampai titik tumbuh.

\section{Diameter Pangkal Batang (mm)}

Diameter pangkal batang diukur menggunakan jangka sorong pada saat tanaman berumur 4, 8 dan 12 MST. Diukur pada bagian pangkal batang yang sudah ditandai dengan kayu sebagai standar pengukuran minggu selanjutnya.

\section{Jumlah Daun (helai)}

Jumlah daun diamati pada saat tanaman berumur 4, 8 dan 12 MST. Daun yang dihitung sudah berwarna hijau dan kasar pada bagian permukaan atasnya saat disentuh, serta sudah terbuka sempurna.

\section{Berat Berangkasan Basah (g)}

Berat basah berangkasan diamati pada akhir penelitian (12 MST) dengan cara membongkar tanaman sampel dan sudah dibersihkan terlebih dahulu, ditimbang menggunakan timbangan digital.

\section{Berat Berangkasan Kering (g)}

Berat kering berangkasan diamati pada akhir penelitian (12 MST) dengan cara ditimbang seluruh bagian tanaman yang terlebih dahulu sudah dibersihkan, dimasukkan dalam amplop dan dioven pada suhu $60^{\circ} \mathrm{C}$ selama $2 \times 24$ jam sudah mencapai berat konstan.

\section{HASIL DAN PEMBAHASAN}

\section{Pengaruh Konsentrasi Mikroorganisme Lokal terhadap Pertumbuhan Bibit Kakao}

Hasil uji F pada analisisis ragam menunjukkan bahwa, pemberian beberapa konsentrasi mikroorganisme lokal berpengaruh tidak nyata terhadap semua parameter yang diamati. 
Tabel 1. Rata-rata pertumbuhan bibit kakao akibat perlakuan konsentrasi mikroorganisme lokal

\begin{tabular}{lcccc}
\hline \multirow{2}{*}{\multicolumn{1}{c}{ Parameter }} & \multicolumn{4}{c}{ Konsentrasi Mikroorganisme Lokal } \\
& 0 & 75 & 150 & $225\left(\mathrm{cc} \mathrm{L}_{3}\right)$ \\
\cline { 2 - 5 } & $\left(\mathrm{M}_{0}\right)$ & $\left(\mathrm{M}_{1}\right)$ & $\left(\mathrm{M}_{2}\right)$ & \\
\hline Tinggi Tanaman 4 MST & 19,65 & 20,38 & 20,33 & 19,67 \\
Tinggi Tanaman 8 MST & 22,64 & 23,81 & 23,45 & 23,14 \\
Tinggi Tanaman 12 MST & 24,11 & 25,92 & 25,03 & 24,97 \\
Diameter Pangkal Batang 4 MST & 3,57 & 3,76 & 3,79 & 3,77 \\
Diameter Pangkal Batang 8 MST & 4,73 & 5,06 & 5,19 & 5,12 \\
Diameter Pangkal Batang 12 MST & 5,74 & 6,05 & 5,96 & 6,00 \\
Jumlah Daun 4 MST & 4,61 & 4,67 & 4,50 & 4,75 \\
Jumlah Daun 8 MST & 10,44 & 10,83 & 11,25 & 10,53 \\
Jumlah Daun 12 MST & 13,06 & 14,19 & 13,59 & 13,89 \\
Berat Berangkasan Basah & 17,01 & 17,47 & 16,00 & 17,87 \\
Berat Berangkasan Kering & 4,16 & 5,32 & 4,43 & 4,44 \\
\hline
\end{tabular}

Tabel 1 menunjukkan bahwa, tinggi tanaman, diameter pangkal batang, jumlah daun, berat berangkasan basah dan berat berangkasan kering pada perlakuan beberapa konsentrasi mikroorganisme lokal berpengaruh tidak nyata, akan tetapi pertumbuhan bibit kakao cenderung lebih baik pada pemberian dosis $75 \mathrm{cc} \mathrm{L}^{-1}$ air $\left(\mathrm{M}_{1}\right)$.

Hasil penelitian ini menunjukkan bahwa, penggunaan mikroorganisme lokal pada konsentrasi yang tinggi dapat menghambat pertumbuhan bibit kakao. Peningkatan konsentrasi mikroorganisme lokal yang tidak disertai dengan peningkatan tinggi tanaman, diameter pangkal batang, jumlah daun, berat berangkasan basah dan berat berangkasan kering. Penelitian Agusni et al. (2016) pemberian mikroorganisme lokal pada konsentrasi yang tinggi menghasilkan jumlah bunga yang semakin rendah pada tanaman kacang hijau. Supriadi (2003) menyatakan tanaman akan tumbuh dan berkembang dengan baik jika unsur hara yang diberikan ke tanaman cukup dan berimbang, sehingga dapat diabsorbsi oleh tanaman

Kualitas larutan MOL ditentukan oleh berbagai macam faktor seperti medium fermentasi, takaran bahan baku atau substrat, dan karekter mikroorganisme yang ikut berperan dalam proses fermentasi, $\mathrm{pH}$, suhu, waktu yang dibutuhkan untuk fermentasi, dan nisbah $\mathrm{C} / \mathrm{N}$ dalam suatu bahan (Seni et al., 2013).

Menurut hasil analisis laboratorium untuk mikroorganisme lokal diketahui bahwa kandungan hara pada mikroorganisme lokal, yaitu N (3,85\%), P (0,12\%), K (2,99\%), pH 3,7 dan $\mathrm{C} / \mathrm{N} 2,9 \%$. Hal ini juga didukung oleh Peraturan Menteri Pertanian (2011) standar mutu pupuk organik cair mengandung N (3-6\%), P (3-6\%), K (3-6\%) dan pH (4-9). Unsur N sudah memenuhi syarat sebagai pupuk organik cair, sedangkan unsur $\mathrm{P}$ dan $\mathrm{K}$ serta $\mathrm{pH}$ belum memenuhi syarat Menteri Pertanian, sehingga dianggap tidak dapat mendukung pertumbuhan bibit kakao.

Tingkat keasaman $(\mathrm{pH})$ dalam suatu bahan berkaitan erat dengan jenis mikroorganisme yang bekerja merombak bahan organik selama proses fermentasi. Rendahnya pH pada MOL kulit pisang dan kulit pepaya diduga menjadi pemicu yang menghambat penyerapan unsur hara dan rendahnya aktivitas mikroorganisme di dalam tanah. Dahlia (2005) dalam Ramli dan Parawansa (2014) menyatakan pada kondisi pH yang asam, ion P akan mudah bersenyawa dengan unsur $\mathrm{Al}, \mathrm{Fe}$ dan $\mathrm{Mn}$, yang mengakibatkan sering terjadinya keracunan tanaman oleh unsur $\mathrm{Al}$ dan $\mathrm{Fe}$ yang berdampak terhadap pertumbuhan akar primer, 
serta menghambat pembentukan akar lateral dan bulu akar. Disamping itu, $\mathrm{pH}$ yang rendah dapat mengurangi aktivitas mikroba sehingga ketersediaan unsur hara melalui proses dekomposisi bahan organik terhambat dan sukar terurai.

Selama proses fermentasi berlangsung rasio $\mathrm{C} / \mathrm{N}$ pada pupuk cair semakin meningkat, hal ini dikarenakan kandungan $\mathrm{C} / \mathrm{N}$ didapatkan dari perbandingan antara kandungan $\mathrm{C}$ organik dan nitrogen, sehingga jika terjadi peningkatan kandungan $\mathrm{C}$ organik maka kandungan $\mathrm{C} / \mathrm{N}$ juga akan semakin meningkat. Sesuai dengan pendapat Alexander (1994) kecepatan degradasi bahan organik ditentukan oleh rasio $\mathrm{C} / \mathrm{N}$. Rasio $\mathrm{C} / \mathrm{N}$ yang rendah akan menghambat perkembangbiakan bakteri, hal ini dipengaruhi oleh peguapan nitrogen menjadi amonium. Sedangkan kandungan rasio $\mathrm{C} / \mathrm{N}$ dalam jumlah yang tinggi akan menyebabkan penguraian bahan organik lebih lambat, hal ini karena nitrogen menjadi penghambat dalam perombakan (growth-rate limitting factor).

Berdasarkan hasil analisis C/N MOL kulit pisang dan kulit pepaya, lama penyimpanan 14 hari menghasilkan $\mathrm{C} / \mathrm{N} 2,9 \%$, sedangkan lama penyimpanan 30 hari menghasilkan $\mathrm{C} / \mathrm{N}$ 13,0\% yang hampir mendekati standar baku dari menteri pertanian. Standar baku mutu pupuk organik cair nisbah $\mathrm{C} / \mathrm{N}$ yang baik adalah berkisar 15\%-25\% (Peraturan Menteri Pertanian, 2010). Hal ini dikarenakan hasil fermentasi dari MOL kulit pisang dan kulit pepaya memiliki kandungan $\mathrm{C}$ organik yang tergolong rendah sehingga menghasilkan kandungan $\mathrm{C} / \mathrm{N}$ yang rendah pula (Cesaria et al., 2014). Oleh karena itu, mikroorganisme lokal dengan masa simpan lebih lama cenderung lebih baik diaplikasikan ke tanaman, karena $\mathrm{C} / \mathrm{N}$ yang dihasilkan lebih tinggi dibandingkan dengan masa simpan yang lebih singkat. Sesuai dengan penelitian Hadiyanto et al. (2012) kondisi optimum untuk penguraian bahan organik pada nilai C/N 21\% diperoleh pada waktu fermentasi 14 hingga 30 hari.

\section{Pengaruh Dosis NPK terhadap Pertumbuhan Bibit Kakao}

Hasil uji F pada analisisis ragam pemberian beberapa dosis pupuk NPK berpengaruh sangat nyata terhadap jumlah daun bibit kakao umur 8 MST, berpengaruh nyata pada umur 12 MST serta berpengaruh nyata terhadap berat berangkasan basah tanaman.

Tabel 2. Rata-rata pertumbuhan bibit kakao akibat perlakuan dosis pupuk NPK

\begin{tabular}{lcccc}
\hline \multirow{1}{*}{\multicolumn{1}{c}{ Parameter }} & \multicolumn{4}{c}{ Dosis Pupuk NPK $(\mathrm{g} /$ polybag $)$} \\
\cline { 2 - 5 } & 0 & 7,5 & 15 & 22,5 \\
& $\left(\mathrm{P}_{0}\right)$ & $\left(\mathrm{P}_{1}\right)$ & $\left(\mathrm{P}_{2}\right)$ & $\left(\mathrm{P}_{3}\right)$ \\
\hline Tinggi Tanaman 4 MST & 20,12 & 20,38 & 19,52 & 20,02 \\
Tinggi Tanaman 8 MST & 22,89 & 24,09 & 22,97 & 24,09 \\
Tinggi Tanaman 12 MST & 24,42 & 26,19 & 24,83 & 24,61 \\
Diameter Pangkal Batang 4 MST & 3,73 & 3,78 & 3,71 & 3,66 \\
Diameter Pangkal Batang 8 MST & $5,13^{2}$ & 5,00 & 5,09 & 4,87 \\
Diameter Pangkal Batang 12 MST & 6,01 & 6,05 & 6,03 & 5,67 \\
Jumlah Daun 4 MST & $4,59^{\mathrm{a}}$ & 4,67 & 4,72 & 4,56 \\
Jumlah Daun 8 MST & $9,53^{\mathrm{a}}$ & $10,50^{\mathrm{a}}$ & $12,61^{\mathrm{b}}$ & $10,42^{\mathrm{a}}$ \\
Jumlah Daun 12 MST & $11,47^{\mathrm{a}}$ & $14,53^{\mathrm{b}}$ & $15,08^{\mathrm{b}}$ & $13,64^{\mathrm{ab}}$ \\
Berat Berangkasan Basah & $14,98^{\mathrm{a}}$ & $18,78^{\mathrm{b}}$ & $18,76^{\mathrm{b}}$ & $15,83^{\mathrm{ab}}$ \\
Berat Berangkasan Kering & $3,77^{\mathrm{b}}$ & 4,91 & 5,13 & 4,54 \\
\hline
\end{tabular}

Keterangan: Angka yang diikuti oleh huruf yang sama pada kolom yang sama berbeda tidak nyata pada uji DNMRT (pada taraf 0,05 ) 
Berdasarkan hasil analisis tanah menunjukkan bahwa tanah tersebut memiliki $\mathrm{pH}$ $(6,99)$, $\mathrm{C}$ organik $(0,62 \%), \mathrm{N}$ total $(0,13 \%), \mathrm{P}_{2} \mathrm{O}_{5}(0,05 \%)$ dan $\mathrm{K}_{2} \mathrm{O}(0,03 \%)$. Unsur hara yang terkadung pada tanah tersebut masih rendah sehingga memerlukan tambahan hara melalui pupuk NPK.

Hasil penelitian ini, pada dosis 7,5 g/polybag $\left(\mathrm{P}_{1}\right)$ mampu menstimulasi pertumbuhan tinggi bibit kakao dibandingkan dengan perlakuan pemberian dosis pupuk NPK lainnya yaitu $26,19 \mathrm{~cm}$ pada umur $12 \mathrm{MST}$. Hal ini dosis optimum untuk pertumbuhan bibit kakao 7,5 $\mathrm{g}$ /polybag yang dapat memenuhi kebutuhan nutrisi bagi pertumbuhan bibit kakao. Menurut Susanto (2003) dalam Yulia et al., (2016) normalnya tinggi bibit kakao pada umur 3 bulan yaitu $25-30 \mathrm{~cm}$.

Perlakuan dosis 7,5 g/polybag $\left(\mathrm{P}_{1}\right)$ menghasilkan diameter pangkal batang terbesar yaitu $6,05 \mathrm{~mm}$ pada umur $12 \mathrm{MST}$. Hal ini merupakan dosis optimum yang mampu meningkatkan diameter pangkal batang. Unsur nitrogen sangat dibutuhkan untuk memacu proses laju fotosintesis tanaman dalam menghasilkan fotosintat yang membantu pertumbuhan diameter pangkal batang (Suriatna, 1988).

Pemberian NPK berpengaruh sangat nyata terhadap pertambahan jumlah daun bibit kakao umur 8 MST dan berpengaruh nyata pada bibit kakao umur 12 MST. Dilihat dari (Tabel 2) perlakuan dosis $15 \mathrm{~g} /$ polybag $\left(\mathrm{P}_{2}\right)$ menghasilkan rata-rata jumlah daun tertinggi yaitu 15,08 helai pada umur 12 MST. Menurut Edriani et al., (2017) unsur N sangat penting bagi produktivitas tanaman. Tanaman yang memiliki daun lebar, berwarna hijau tua mengandung unsur $\mathrm{N}$ yang cukup, dikarenakan proses fotosintesis berjalan dengan baik. Hal ini juga didukung oleh pernyataan Lingga dan Marsono (2009) nitrogen merupakan unsur hara essensial yang sangat dibutuhkan dalam fase pertumbuhan vegetatif tanaman.

Parameter berat berangkasan basah, nilai tertinggi diperoleh pada perlakuan dosis 7,5 $\mathrm{g} /$ polybag $\left(\mathrm{P}_{1}\right)$ yaitu $18,78 \mathrm{~g}$, walaupun tidak berbeda nyata dengan perlakuan lainnya. Berat berangkasan basah menurun pada dosis pupuk NPK yang lebih tinggi. Hal ini sesuai dengan hasil penelitian Novizan (2005) dalam Nasrullah (2015) yang menyatakan bahwa pemberian pupuk nitrogen dalam jumlah yang berlebihan di dalam tanah akan meningkatkan konsentrasi ion $\mathrm{H}^{+}$, sehingga $\mathrm{pH}$ tanah menurun dan tanah menjadi lebih masam. Selain itu unsur hara menjadi dalam bentuk tidak tersedia bagi tanaman yang dapat menyebabkan terhambatnya pertumbuhan tanaman.

Pemberian pupuk NPK pada berbagai dosis berpengaruh tidak nyata terhadap berat berangkasan kering. Akan tetapi jika dilihat secara keseluruhan, pada perlakuan dosis 15 g/polybag $\left(\mathrm{P}_{2}\right)$ memberikan hasil terbaik, yaitu 5,1 g dibandingkan dengan perlakuan lainnya. Menurut Burhanuddin (1996) dalam Yulia et al., (2016) bobot kering tanaman dipengaruhi oleh jumlah, ukuran dan kualitas sel sebagai penyusun tanaman dan pada umumnya terdiri dari $70 \%$ air, hal ini juga tergantung oleh penyerapan unsur hara bagi tanaman.

\section{KESIMPULAN DAN SARAN}

Konsentrasi mikroorganisme lokal berpengaruh tidak nyata terhadap semua parameter yang diamati, namun pertumbuhan bibit kakao cenderung lebih baik diperoleh pada konsentrasi $75 \mathrm{cc} \mathrm{L}^{-1}$ air. Dosis pupuk NPK berpengaruh sangat terhadap jumlah daun bibit kakao umur $8 \mathrm{MST}$, berpengaruh nyata terhadap jumlah daun bibit kakao umur $12 \mathrm{MST}$ dan berat berangkasan basah. Pertumbuhan bibit kakao terbaik diperoleh pada dosis $15 \mathrm{~g} /$ polybag. Terdapat interkasi tidak nyata antara perlakuan konsentrasi mikroorganisme lokal dan dosis pupuk NPK. 
Berdasarkan hasil penelitian disarankan untuk penggunaan mikroorganisme lokal sebaiknya disimpan terlebih dahulu selama 1 bulan setelah fermentasi agar kandungan $\mathrm{C} / \mathrm{N}$ yang diperoleh sesuai dengan anjuran pemerintah yaitu $15-25 \%$, serta penelitian lanjutan mengenai identifikasi mikroba yang terkandung dalam mikroorganisme lokal.

\section{DAFTAR PUSTAKA}

Alexander, M. 1994. Biodegradation and Bioremediation. United States of America: Academic Press, Inc. Balai Penelitian Ternak-Balitnak.

Agusni. Millatina dan H. Satriawan. 2016. Pengaruh penggunaan mikro organisme lokal limbah rumah tangga dan NPK terhadap pertumbuhan dan hasil tanaman kacang hijau (Vigna radiata L). Jurnal Agrotropika Hayati. 3(3): 11-20.

Cesaria, R. Y., R. Wirosoedarmo dan B. Suharto. 2014. Pengaruh penggunaan starter terhadap kualitas fermentasi limbah cair tapioka sebagai alternative pupuk cair. Jurnal Sumberdaya Alam dan Lingkungan. 1(1): 8-14.

Edriani, F. Ardiansyah dan Sarman. 2017. Respon pertumbuhan bibit kakao (Theobroma cacao L.) pada campuran pupuk biourine sapi dengan pupuk NPK bervariasi. Repository Unja. 1-11.

Hadiyanto, Subandriyo dan D. D. Anggoro. 2012. Optimasi pengomposan sampah organik rumah tangga menggunakan kombinasi aktivator EM4 dan mol terhadap rasio $\mathrm{C} / \mathrm{N}$. Jurnal Ilmu Lingkungan. 10(2): 70-75.

Jannah, I. M. 2014. Pengaruh media tanam dan dosis pemupukan NPK Phonska (15:15:15) terhadap pertumbuhan bibit kakao (Theobroma cacao L.). Skripsi. Program Studi Agroteknologi, Fakultas Pertanian Universitas Syiah Kuala, Banda Aceh.

Lingga, P. dan Marsono. 2009. Petunjuk Penggunaan Pupuk. Penebar Swadaya. Jakarta.

Nasrullah. 2015. Pengaruh dosis pupuk NPK (16:16:16) dan mikoriza terhadap pertumbuhan bibit kakao (Theobroma cacao L.) pada media tumbuh subsoil. Skripsi. Program Studi Agroteknologi, Fakultas Pertanian Universitas Syiah Kuala, Banda Aceh.

Peraturan Menteri Pertanian. 2011. Standar Mutu Pupuk Organik Cair. https://nasih.files.wordpress.com/2011/11/lampiran-i. Diakses tanggal: 27 Agustus 2018.

Pranata, A. S. 2004. Pupuk Organik Cair Aplikasi dan Manfaatnya. Agromedia Pustaka, Jakarta.

Rahayu, L. S. 2017. Pengaruh pupuk organik cair (POC) dari mol pepaya terhadap pertumbuhan dan produktivitas tanaman cabai rawit (Capsicum frutescens L.). Skripsi. Program Studi Pendidikan Biologi, Fakultas Keguruan dan Ilmu Pendidikan Universitas Nusantara PGRI, Kediri. 
Ramli dan I. NR. Parawansa. 2014. Mikroorganisme lokal (MOL) buah pisang dan pepaya terhadap pertumbuhan tanaman ubi jalar (Ipomea batatas L.). Jurnal Agrisistem. 1 (10): 10-15.

Rifin, A. dan Nurdiyani, F. 2007. Integrasi pasar kakao Indonesia. Jurnal Agribisnis dan Ekonomi Pertanian. 1 (2): 1-12.

Seni, I.A.Y., I.W.D Atmaja., N.W.S Sutari. 2013. Analisis kualitas larutan MOL (mikroorganisme lokal) berbasis daun gamal (Gliricidia sepium). E-Jurnal Agroteknologi Tropika. 2(2): 135-144.

Supriadi, G. 2003. Sifat dan Ciri Tanah. Fakultas Pertanian Institut Pertanian. Bogor.

Suriatna, S. 1988. Pupuk dan Pemupukan. Mediyatma Sarana. Jakarta.

Wijaya. 2017. Fungsi, Manfaat dan Cara Membuat MOL Buah. http://cipanasfarm.com/fungsi-dan-manfaat-dan-cara-membuat-mol-buah. Diakses tanggal: 2 Mei 2018.

Yulia, A. E., F. Triastuti dan Wardati. 2016. Pengaruh pupuk kascing dan pupuk NPK terhadap pertumbuhan bibit tanaman kakao (Theobroma cacao L.). Jurnal Faperta. 1 (3): $1-13$. 